\title{
Quantifying Disaster Physical Damage Using Remote Sensing Data-A Technical Work Flow and Case Study of the 2014 Ludian Earthquake in China
}

\author{
Yida Fan' ${ }^{1}$ Qi Wen ${ }^{2} \cdot$ Wei Wang ${ }^{2} \cdot$ Ping Wang ${ }^{2} \cdot$ Lingling $\mathrm{Li}^{2} \cdot$ Peng Zhang ${ }^{2}$
}

Published online: 20 September 2017

(C) The Author(s) 2017. This article is an open access publication

\begin{abstract}
Disaster damage assessment is an important basis for the objective assessment of the social impacts of disasters and for the planning of recovery and reconstruction. It is also an important research field with regard to disaster mitigation and risk management. Quantitative assessment of physical damage refers to the determination of the physical damage state of the exposed elements in a disaster area, reflecting the aggregate quantities of damages. It plays a key role in the comprehensive damage assessment of major natural hazard-induced disasters. The National Disaster Reduction Center of China has established a technical work flow for the quantitative assessment of disaster physical damage using remote sensing data. This article presents a quantitative assessment index system and method that can be integrated with high-resolution remote sensing data, basic geographical data, and field survey data. Following the 2014 Ludian Earthquake in Yunnan Province, China, this work flow was used to assess the damage to buildings, roads, and agricultural and forest resources, and the assessment results were incorporated into the Disaster Damage Comprehensive Assessment Report of the 2014 Ludian Earthquake for the State Council of China. This article also outlines some possible improvements that can be addressed in future work.
\end{abstract}

Qi Wen

whistlewen@aliyun.com

1 Information Center, Ministry of Civil Affairs, Beijing 100721, China

2 National Disaster Reduction Center of China, Ministry of Civil Affairs, Beijing 100124, China
Keywords China · Disaster damage assessment · Ludian Earthquake · Quantitative physical damage assessment $\cdot$ Remote sensing in damage assessment

\section{Introduction}

Natural hazard-induced disasters are continually eroding the achievements of human progress, with far-reaching negative effects on people's livelihoods, and they are obstacles to sustainable social and economic development. Disaster damage assessment plays an important role in many areas. It helps to understand the characteristics of disaster damage, provides an objective assessment of the social impacts of disasters, helps to guide rescue and relief operations, and forms the basis for the planning of recovery and reconstruction in disaster regions, as well as for the development of plans to prevent and mitigate future disasters. Disaster damage assessment is thus a major research topic in the study of natural hazards and disaster risk management.

Remote sensing technology has a long history of application in disaster damage assessment. There are many satellites in orbit that are equipped with various remote sensing payloads, and these are supplemented by the use of airborne remote sensing and other unmanned aerial vehicles (UAVs). As a result, there now exists a collaboratively operated network involving multiple satellite observations, airborne remote sensing, and ground observations. Hence, there have been marked improvements in temporal and spatial resolutions and in the quantifiable level of remote sensing data, offering ample data sources for the assessment of physical damage due to natural hazards and disasters. 
In recent years, remote sensing technology has achieved much progress in its application to research on seismic disasters (Ehrlich et al. 2009; Wen, Xu et al. 2011; Yang et al. 2011), flood disasters (Stramondo et al. 2006), geological disasters (Graciela et al. 2005; Wen, He et al. 2011), droughts (Du et al. 2013), blizzards (Liang et al. 2008), and fire disasters (Veraverbeke et al. 2010). There have been continuous developments of the technology for assessing disaster physical damage (Fan et al. 2008; Cao et al. 2015; Nie et al. 2016), which have been applied to comprehensive damage assessment for several major natural disasters. During the 2003 Bam, Iran, Earthquake, data from IKONOS (Chiroiu 2005), Quickbird (Yamazaki et al. 2005), Terra-ASTER (Kohiyama and Yamazaki 2005), and Envisat/ASAR (Matsuoka and Yamazaki 2005), together with other remote sensing data, were used to assess building damage. During the 2010 Haiti Earthquake, data from the Worldview satellite, together with data from highresolution airborne and multi-angle oblique photography remote sensing, were utilized in disaster damage assessment (Corbane et al. 2011), providing quantitative results on building damage. During the 2010 Chile Earthquake (Maruyama et al. 2012) and the 2011 Japan Earthquake and Tsunami (Liu et al. 2013), high-resolution remote sensing data were also used for damage assessment.

However, most research has focused on buildings and infrastructure, without moving toward the construction of an index system that provides comprehensive assessment of disaster damage in an area. Even when detailed attention was paid to the development of algorithms for comprehensive damage assessment, there still has been a lack of consideration of the overall implementation of a standard work flow. This has led to uncertainties in the index system for damage assessment and in the adoption of work flows and methods. It is necessary to develop a complete index system and systematic process for disaster damage assessment.

In the past decade, China has faced a number of extraordinarily serious natural hazard-induced disasters, including the 2008 Wenchuan Earthquake, the 2010 Yushu Earthquake, the 2010 Zhouqu Debris Flow, the 2013 Lushan Earthquake, and the 2014 Ludian Earthquake. The National Commission for Disaster Reduction and the Ministry of Civil Affairs have thus set up a systematic program of comprehensive damage assessment for major natural hazard-induced disasters and have gradually developed and optimized a comprehensive approach to damage assessment that involves disaster extent assessment, quantitative assessment of physical damage, direct economic loss assessment, the construction of an index system, and the application of modeling algorithms. Disaster extent assessment refers to the delineation of the extent of a major natural hazard-induced disaster and the determination of the damage state. Quantitative assessment of physical damage refers to the determination of the physical damage to the exposed elements within the disaster extent, together with an assessment of the damage state, to obtain quantitative damage assessment results that reflect the aggregate quantities of damages for an exposure unit. Direct economic loss assessment refers to the use of the quantitative assessment results of physical damage as the basis for calculating the value of economic losses, that is the replacement cost. Among these aspects, the quantitative assessment of physical damage plays a linking role. It directly determines the precision of the overall damage assessment and the quantifiable levels, making it both a focus and a possible hurdle to be overcome in the comprehensive assessment of a disaster. Disaster damage assessment includes exposed urban and rural buildings; infrastructure; the agricultural, industrial, and public service sectors; natural resources; household property; and other assets. The measurement generally can be the number of units, length, area, and damage state, depending on the type of exposed elements and administrative units. In recent practical applications of disaster loss assessment, the Ministry of Civil Affairs of China has attempted to quantify disaster damage using remote sensing data (Experts Group for Earthquake Disaster Relief, National Disaster Reduction Committee and Ministry of Science and Technology 2008; Fan 2014), which has dramatically reduced the dependence on ground investigation work and has allowed a more objective and comprehensive quantitative assessment of losses.

Based on a summary of China's practical experience with comprehensive damage assessment work for major natural hazard-induced disasters since 2008, and focusing primarily on quantitative assessments of disaster physical damage, this article presents a work flow including an index system and method for damage assessment, while also incorporating the relevant requirements of the Major Natural Disaster Damage Statistics System promulgated by the Ministry of Civil Affairs in 2014 (Ministry of Civil Affairs and National Bureau of Statistics 2014). Taking the 2014 magnitude 6.5 Ludian Earthquake in Yunnan Province as an example, the process and results of the assessment are described in the case study section.

\section{Natural Hazard-Induced Disasters: Physical Damage Assessment Index System}

In order to establish and standardize an statistical approach and index system for the assessment of major natural hazard-induced disaster damage and to provide a basis for decision making with regard to disaster region recovery and reconstruction plans for both the central and local 
governments, the China National Commission for Disaster Reduction and the Ministry of Civil Affairs, with the approval of the National Bureau of Statistics, released the Major Natural Disaster Damage Statistics System in 2014 (Ministry of Civil Affairs and National Bureau of Statistics 2014). This system prescribes in detail the major aspects of the statistical data required in the case of a natural hazardinduced disaster, including personal damage; building damage; household property damage; agricultural, industrial, and service industry damage; infrastructure damage; public service systems damage; and resources and environmental damage, together with other indices. The selected hazard-affected elements could be quantitatively assessed using remote sensing data by means of visual interpretation or automatic algorithm identification, and on this basis the index system for quantitative assessment of disaster physical damage using remote sensing data was formulated. Of the aspects included in the statistical system, some-the afflicted population, household property damage, service industry (tertiary industry) damage, and public service systems damage-are excluded from the coverage of remote sensing assessment. Thus, the developed index system primarily focuses on buildings, the agricultural and industrial sectors, infrastructure, and the resources and environment systems (Table 1).

\section{Assessment Method}

This study presents the assessment method that can obtain quantified assessment results of various hazard-affected elements with different damage states within the whole disaster region based on an index system. A wide range of satellite remote sensing data, very high spatial resolution remote sensing data of UAVs, and field survey data from investigation sites can be incorporated into this method. Pre-disaster background information from satellite remote sensing may be obtained daily, and UAVs can start immediately after a disaster. This method is especially suitable for rapid disaster damage assessment.

First, pre-disaster background information of different hazard-affected elements are prepared by using high resolution remote sensing data, basic geographical data, and statistical data. Second, UAV remote sensing data of selected typical disaster-affected areas are acquired, and damage proportion matrices of various hazard-affected elements with different damage states are calculated through image interpretation. Then, the proportion matrices are calibrated by field survey data from investigation sites by field survey experts. Finally, quantified physical damage assessment results are obtained by using GIS analysis and calculation. Figure 1 shows a schematic diagram of the assessment method.
The calculation process can also be represented by Eq. 1:

$$
\begin{aligned}
D & =\left(e_{m} B\right) \cdot R_{\text {sample }}=\left[\begin{array}{ccc}
b_{1} & \cdots & b_{n} \\
\vdots & \ddots & \vdots \\
b_{1} & \cdots & b_{n}
\end{array}\right] \cdot\left[\begin{array}{ccc}
r_{11} & \cdots & r_{1 n} \\
\vdots & \ddots & \vdots \\
r_{m 1} & \cdots & r_{m n}
\end{array}\right] \\
& =\left[\begin{array}{ccc}
r_{11} b_{1} & \cdots & r_{1 n} b_{n} \\
\vdots & \ddots & \vdots \\
r_{m 1} b_{1} & \cdots & r_{m n} b_{n}
\end{array}\right]=\left[\begin{array}{ccc}
d_{11} & \cdots & d_{1 n} \\
\vdots & \ddots & \vdots \\
d_{m 1} & \cdots & d_{m n}
\end{array}\right]
\end{aligned}
$$

where $D$ is the total damage quantity matrix for a category of hazard-affected element, $d_{i j}$ denotes the quantity of the $j$ th subcategory of hazard-affected element with the $i$ th damage state, $\sum_{i=1}^{m} d_{i j}=\sum_{i=1}^{m} r_{i j} b_{j}=b_{j} . e_{m}$ is a $m$-dimensional column vector with all elements equal to $1 . B=$ $\left[b_{1}, b_{2}, \ldots, b_{n}\right]$ denotes the basic quantity of a category of hazard-affected element, and $b_{j}$ denotes the total quantity of a given subcategory of hazard-affected element. $R_{\text {sample }}=\left[\begin{array}{ccc}r_{11} & \cdots & r_{1 n} \\ \vdots & \ddots & \vdots \\ r_{m 1} & \cdots & r_{m n}\end{array}\right]$ denotes the calibrated damage proportion matrix of hazard-affected elements within the remote sensing sample observation area, $r_{i j}$ denotes the calibrated damage proportion of the $j$ th category, and the $i$ th damage state of a hazard-affected element, $\sum_{i=1}^{m} r_{i j}=1$. And - is the Hadamard operator over matrices.

\subsection{Background Information Extraction for Hazard-Affected Elements}

Background information is mainly a database that contains the vector spatial extent of hazard-affected elements in areas of high vulnerability and risk with their essential attributes for damage assessment. This database can be prepared by extraction from pre-disaster raster remote sensing images, collection of open geographical data, online map data and navigational data, and vectorization of statistical data. According to the index system, background information preparation concerns mainly four categories of disaster-affected elements: buildings, the agricultural and industrial sectors, infrastructure, and resources. Although different types of natural hazards inflict varying levels of damage on the different elements in an exposed area, these physical structures, activities, and resources concentrate the majority of the material wealth and thus are the main objects of damage assessment.

\subsubsection{Buildings}

Using earthquakes as an example, according to the assessment results for the earthquake disasters in 
Table 1 The index system for quantitative assessment of disaster physical damage using remote sensing data developed in China

\begin{tabular}{|c|c|c|c|c|c|}
\hline Category & Subcategory & Division & Subdivision & $\begin{array}{l}\text { Quantifiable } \\
\text { index }\end{array}$ & State \\
\hline \multirow[t]{3}{*}{ Buildings } & \multirow[t]{2}{*}{ Residential } & Rural & $\begin{array}{l}\text { Steel-concrete, brick-concrete, } \\
\text { brick-wood, other }\end{array}$ & $\begin{array}{l}\text { Household, } \\
\text { room }\end{array}$ & $\begin{array}{l}\text { Collapse, serious } \\
\text { damage, moderate } \\
\text { damage }\end{array}$ \\
\hline & & \multirow[t]{2}{*}{ Urban } & \multirow[t]{2}{*}{$\begin{array}{l}\text { Steel-concrete, brick-concrete, } \\
\text { brick-wood, other }\end{array}$} & $\begin{array}{l}\text { Household, } \\
\text { area }\end{array}$ & $\begin{array}{l}\text { Collapse, serious } \\
\text { damage, moderate } \\
\text { damage }\end{array}$ \\
\hline & Non-residential & & & Area & $\begin{array}{l}\text { Collapse, serious } \\
\text { damage, moderate } \\
\text { damage }\end{array}$ \\
\hline \multirow{4}{*}{$\begin{array}{l}\text { Agricultural and } \\
\text { industrial } \\
\text { sectors }\end{array}$} & \multirow[t]{3}{*}{ Agriculture } & \multirow[t]{2}{*}{ Farming } & Crops & Area & $\begin{array}{l}\text { Affected, moderate loss, } \\
\text { no harvest }\end{array}$ \\
\hline & & & Greenhouses & Area & \multirow[t]{3}{*}{ Impaired } \\
\hline & & Forestry & $\begin{array}{l}\text { Forests, bushes, woodland, nursery } \\
\text { breeding }\end{array}$ & Area & \\
\hline & Industry & Factory/warehouse & & Area & \\
\hline \multirow[t]{13}{*}{ Infrastructure } & \multirow[t]{4}{*}{ Transportation } & Roads & $\begin{array}{l}\text { Various grades of road (road } \\
\text { foundations, road surfaces, } \\
\text { bridges) }\end{array}$ & Length & \multirow[t]{13}{*}{ Impaired } \\
\hline & & Rail & $\begin{array}{l}\text { Various types of rails (rail } \\
\text { foundations, bridges) }\end{array}$ & Length & \\
\hline & & Shipping & Locks, harbors & Number & \\
\hline & & Air & Airports & Number & \\
\hline & Communications & $\begin{array}{l}\text { Communication } \\
\text { networks }\end{array}$ & Base stations & Number & \\
\hline & Energy & Electricity & Transformer equipment & & \\
\hline & \multirow[t]{3}{*}{$\begin{array}{l}\text { Water } \\
\text { conservancy }\end{array}$} & \multirow[t]{2}{*}{$\begin{array}{l}\text { Flood protection } \\
\text { infrastructure }\end{array}$} & $\begin{array}{l}\text { Various sizes of reservoirs, dikes, } \\
\text { sluices, dams }\end{array}$ & Number & \\
\hline & & & Levees & Length & \\
\hline & & $\begin{array}{l}\text { Drinking water } \\
\text { projects }\end{array}$ & Channels & Length & \\
\hline & \multirow[t]{2}{*}{$\begin{array}{l}\text { Municipal } \\
\text { infrastructure }\end{array}$} & $\begin{array}{l}\text { Municipal } \\
\text { transportation } \\
\text { infrastructure }\end{array}$ & $\begin{array}{l}\text { Roads, bridges, rail transportation } \\
\text { lines }\end{array}$ & Length, & \\
\hline & & Municipal greenery & Rail transportation stations, nodes & Area & \\
\hline & $\begin{array}{l}\text { Rural } \\
\text { infrastructure }\end{array}$ & \multirow[t]{2}{*}{ Rural roads } & & Length & \\
\hline & $\begin{array}{l}\text { Geological } \\
\text { disaster } \\
\text { prevention }\end{array}$ & & $\begin{array}{l}\text { Rock fall, landslide, mud flow, } \\
\text { subsidence, and fissure prevention }\end{array}$ & Number & \\
\hline \multirow[t]{2}{*}{ Resources } & \multirow[t]{2}{*}{$\begin{array}{l}\text { Resources and } \\
\text { environment }\end{array}$} & $\begin{array}{l}\text { Land resources and } \\
\text { mining }\end{array}$ & Arable land, forest land, grassland & Area & Damage \\
\hline & & $\begin{array}{l}\text { Environmental } \\
\text { damage }\end{array}$ & Surface water & & \\
\hline
\end{tabular}

Wenchuan, Yushu, Lushan, and Ludian, direct economic losses caused by building damage usually account for approximately $50 \%$ of the total losses, and building damage is an important aspect for assessment. The direct economic loss caused by building damage can be calculated by multiplying the number of rooms of damaged buildings with various structure types and damage states, the loss rate, and construction cost. The calculation process can also be represented by Eq. 2:

$L_{\mathrm{b}}=\sum_{i=1}^{n} \sum_{j=1}^{m} d_{i j} \cdot \eta_{i j} \cdot C_{i}$

where $L_{\mathrm{b}}$ denotes the direct economic loss that resulted from building damage, $d_{i j}$ denotes the number of rooms of 


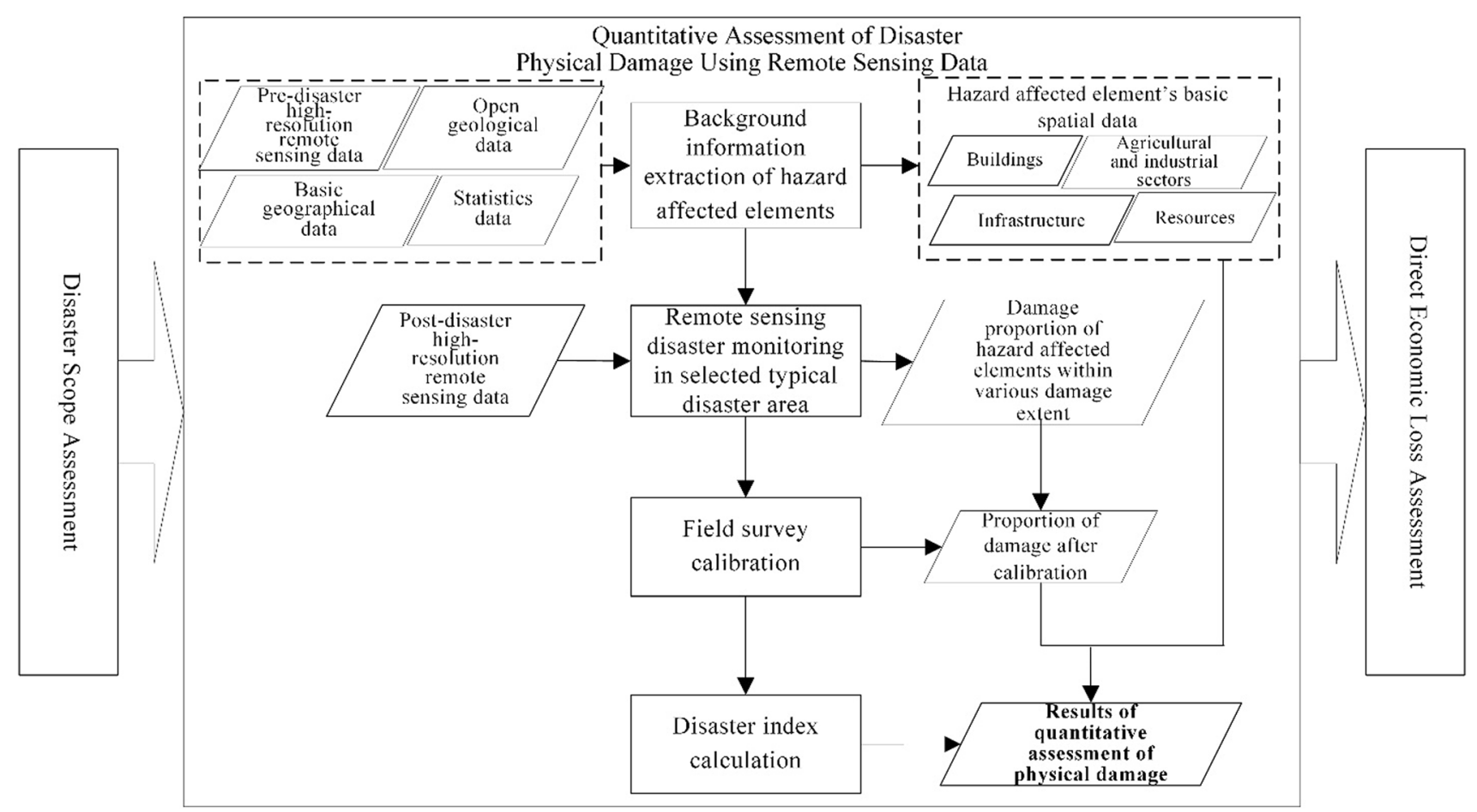

Fig. 1 Schematic diagram of the quantitative assessment of disaster physical damage using remote sensing data method developed in China

the $j$ th structure type of buildings with the $i$ th damage state and can be calculated by the number of rooms of each storey multiplying the number of storeys, $\eta_{i j}$ denotes the loss rate, which is a coefficient percentage corresponding to the damage state, and $C_{i}$ denotes the construction cost of buildings with the $i$ th structure type.

Hence, besides the spatial extent of buildings, background information of a building always includes four attributes: number of rooms, number of storeys, structure type, and construction cost.

Spatial extent of buildings Using pre-disaster high-spatial resolution satellite and airborne remote sensing data, vector data of building spatial extent within high-risk areas can be obtained by the semiautomatic interactive building outline extraction method (Deng and Manjunath 2001) or by visual interpretation with the aid of GIS software.

Number of rooms The number of rooms of each storey can be inferred by dividing the area within the outline of a building by the average area of rooms. The average area of rooms within a certain region is generally acquired from field survey or statistical data.

Number of storeys Building height can be estimated through building shadow extraction from pre-disaster remote sensing images in conjunction with an imaging geometric model between building and shadow (Ye et al. 2008). On the assumption of $3 \mathrm{~m}$ height per storey, the number of storeys of each building can be calculated from the building height.
Structure type According to the Major Natural Disaster Damage Statistics System (Ministry of Civil Affairs and National Bureau of Statistics 2014), rural and urban building structure types are divided into four categories in China: steel-concrete, brick-concrete, brick-wood, and others. This attribute can be determined through roof style and storey height (Table 2) based on visual interpretation of remote sensing images. At the same time, because orthographic remote sensing imaging is unable to observe the walls or the interiors of buildings, mistakes may always exist in interpreting structure types. Therefore, it is necessary to consult statistical data for the proportion of each structure type within the area, and field survey data can also be referred to for calibration.

Construction cost This attribute is related to structure type. Buildings with the same structure type always have the same average construction cost within a certain region. The value is acquired from field survey or statistical data.

\subsubsection{Agricultural and Industrial Sectors}

In major natural hazard-induced disasters, direct economic losses caused by agricultural and industrial sector damage can account for approximately 10-20\% of the total loss. Categories that can be assessed using remote sensing technology primarily include farming, forestry, factories, and warehouses used in agriculture and industry. 
Table 2 Characteristics of various building structure types in China

\begin{tabular}{lllll}
\hline $\begin{array}{l}\text { Structure } \\
\text { type }\end{array}$ & Storeys & Type of roof & Region & Usage \\
\hline $\begin{array}{c}\text { Steel- } \\
\text { concrete } \\
\begin{array}{c}\text { Brick- } \\
\text { concrete }\end{array}\end{array}$ & Relatively high, more than 2 storeys & Flat roof & $\begin{array}{c}\text { Urban } \\
\text { center } \\
\text { Rural }\end{array}$ & $\begin{array}{c}\text { Urban residence, store/shopping center, office } \\
\text { building } \\
\text { Rural residence, factory }\end{array}$ \\
$\begin{array}{c}\text { Brick-wood } \\
\text { Other }\end{array}$ & $\begin{array}{c}\text { Bungalow, 1-2 storeys } \\
\text { Relatively low, 1-1.5 storeys, half-storey } \\
\text { attics }\end{array}$ & $\begin{array}{c}\text { A-frame slanted } \\
\text { roof } \\
\text { A-frame slanted } \\
\text { roof }\end{array}$ & $\begin{array}{c}\text { Rural } \\
\text { Remote } \\
\text { rural }\end{array}$ & Residence, auxiliary rooms \\
\hline
\end{tabular}

For farming and forestry, data from the Second National Land Survey (Wang and Zhou 2009) can be used as the primary reference. From 2007 to 2009, China implemented the Second National Land Survey project using remote sensing, GIS, and GPS technologies and field surveys, in order to determine the land use status over the whole country and to obtain basic data. The Second National Land Survey data are the latest and most complete collection of land use data in China, and include the boundary, type, and distribution for each plot of rural and urban land. Information on type, extent, area, and other attributes, can be obtained for arable land, orchards, forests, and grasslands from the Second National Land Survey data, together with information on crop and forest types from the classification of pre-disaster high-resolution remote sensing images. Greenhouses in agriculture and warehouses and factories in industry can be identified through visual interpretation of high-resolution pre-disaster remote sensing data, with methods similar to those used for buildings.

\subsubsection{Infrastructure}

In past major disasters, direct economic losses of infrastructure due to damage can account for between 20 and $35 \%$ of the total loss, which is a relatively large proportion. Because infrastructure usually covers relatively large areas, satellite remote sensing can observe infrastructure clearly. Background information of transportation and municipal infrastructure can be obtained from the national 1:25,000 basic geographical data, OpenStreetMap, and other open geographical data. It is also possible to refer to online maps and navigational data to interpret transportation infrastructures. There is usually a lack of data on rural roads in the above data, but pre-disaster high-resolution remote sensing data can be used to extract rural road vector data and to label road levels (Zhang et al. 2011). Background information of communication, energy, and hydro-infrastructure can be extracted from the Second National Land
Survey data and through visual interpretation of high-resolution remote sensing data.

\subsubsection{Resources}

Background information of resources can be obtained directly from the Second National Land Survey data according to the QADPDRSD index system. Environmental and disaster reduction satellite data (Fan et al. 2012), GF-1 (Zhang et al. 2015), GF-4 (Wang and He 2017), and ZY-3 (Wang et al. 2015) satellite data can also be used as base images to generate land cover datasets for high-risk areas by using segmentation, classification, and artificial revision methods, such as ChinaCover (Wu et al. 2013).

\subsection{Post-Disaster Remote Sensing Monitoring}

In a major natural hazard-induced disaster, hazard-affected elements usually have roughly similar damage conditions within a given disaster area with the same disaster intensity. Therefore, when disasters occur, it is not necessary to monitor the complete disaster affected region, so long as, based on a preliminary assessment of the spatial extent of impact, remote sensing platforms, such as satellite, airplane, UAV, fly over some selected typical areas to monitor hazard-affected elements in various damage states. Remote sensing monitoring of selected disaster-affected areas involves four steps: remote sensing monitoring, construction of interpretation keys, damage state assignment, and damage proportion calculation. First, background information of hazard-affected elements provides the overall quantity and spatial distribution of exposure. When post-disaster remote sensing images of selected typical areas are acquired, remote sensing interpretation keys for various hazard-affected elements in various damage states for the specific type of disasters are constructed to guide visual interpretation. Then, the damage 
state attribute for each target within the monitored area is labeled. Finally, the damage proportion matrix is obtained using GIS tools. Figure 2 illustrates the process of postdisaster remote sensing monitoring in selected areas.

\subsubsection{Buildings}

The important issues for post-disaster remote sensing monitoring are choice of typical disaster area, spatial resolution, damage state determination, and damage proportion calculation.

Typical disaster area Compact residential areas in rural and urban districts are often selected as typical disaster areas because they have buildings with relatively complete structure types.

Spatial resolution As buildings are normally small in size, post-disaster remote sensing images of approximately $0.1 \mathrm{~m}$ resolution from UAVs are usually used for interpretation.

Damage state Building damage has different forms in remote sensing images from different disasters. For earthquakes, by referring to the criteria of the European Macroseismic Scale 1998 (Grünthal 1998) and considering actual earthquake experiences in China, building damage condition in the quantitative assessment index system is divided into four states: totally collapsed, seriously damaged, moderately damaged, and undamaged. Table 3 lists buildings with different structure types and in different damage states in remote sensing images after an earthquake disaster. For geological disasters such as landslides and mud slides, it is possible to assign damage state based on whether the building structure has been damaged, the position relative to the geological disaster area, and the degree of burial. Remote sensing interpretation keys are produced according to the damage description. Comparing

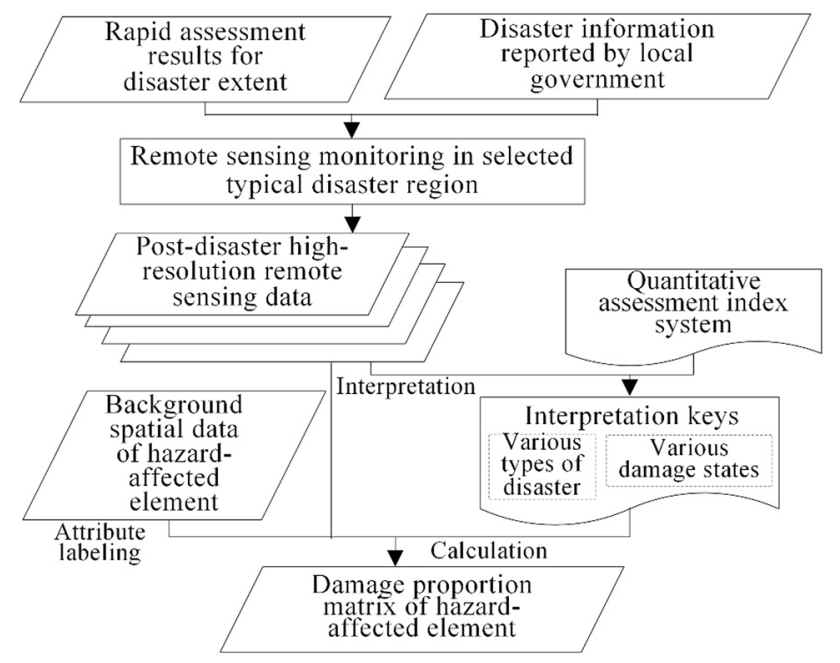

Fig. 2 Diagram of a post-disaster remote sensing monitoring process pre-disaster and post-disaster remote sensing data, the damage state attribute can be assigned by using the automatic change detection method (Liu et al. 2010) or visual interpretation.

Damage proportion For different hazard intensities, buildings of different structure types always have different damage proportions for each damage state. For earthquakes, seismic intensity can represent hazard intensity; buildings of the same structure type within areas with the same seismic intensity degree are regarded as having the same damage proportion. For geological disasters, there is usually one kind of damage condition within a specific disaster intensity, so the damage proportion is $100 \%$ for this damage state, but zero for others.

A two-dimensional damage proportion matrix is calculated by considering the proportions of various damage states for different structure types using GIS software, which has the same table structure as Table 3. This matrix from selected disaster areas represents the damage condition of the whole disaster-affected region.

\subsubsection{Other Hazard-Affected Elements}

Both cropland damage and yield reduction caused by natural hazard-induced disasters lead to agriculture production losses ( $\mathrm{Li}$ et al. 2009). The damage state for farming is divided into four categories: no harvest, moderate loss, affected, and undamaged. By extraction of coverage of geological disasters, barrier lakes, and floods from postdisaster airborne remote sensing images and overlaying pre-disaster background data, the damage area and damage proportion matrix of a farming area can be obtained. Yields of various crops within selected remote sensing monitoring areas are estimated using crop growth trend models and yield estimation models. Combined with data on crop damage areas and yield information, damaged output can be estimated. Figure 3 illustrates the process of farmland damage assessment. Forest stock volume damage can be estimated using a similar process as for farmland, and, using Thematic Mapper (TM) and other satellite data, the forest stock volume of selected monitoring areas can be estimated (Tomppo et al. 2002) and the damage proportions then can be obtained (Wang et al. 2010; Zhao et al. 2014).

Primary infrastructure is mainly distributed in populated urban and rural areas, and thus typical built-up areas are often monitored. For factories and warehouses of primary and secondary industries, infrastructure, and other normally relatively large objects, high-resolution satellite remote sensing data (WorldView, Quickbird, Terrasar-X, and others) and airborne remote sensing data $(0.4-0.5 \mathrm{~m})$ are used. For large hazard-affected elements such as those related to resources and the general environment, for 
Table 3 Description of building damage states in remote sensing images ( $0.1 \mathrm{~m}$ resolution) after an earthquake disaster

\begin{tabular}{|c|c|c|c|c|}
\hline $\begin{array}{l}\text { Structure } \\
\text { type }\end{array}$ & Undamaged & Moderately damaged & Seriously damaged & Totally collapsed \\
\hline $\begin{array}{l}\text { Steel- } \\
\text { concrete }\end{array}$ & \multicolumn{2}{|c|}{$\begin{array}{l}\text { Building outline intact, clear roof edges, even roof with uniform } \\
\text { color, occasionally dispersed rubble around }\end{array}$} & \multicolumn{2}{|c|}{$\begin{array}{l}\text { Building outline relatively intact, smashed roof with ununiform } \\
\text { colors, some dispersed rubble around }\end{array}$} \\
\hline $\begin{array}{l}\text { Brick- } \\
\text { concrete }\end{array}$ & $\begin{array}{l}\text { Building outline intact, clear } \\
\text { roof edges, flat and even roof } \\
\text { with uniform color }\end{array}$ & $\begin{array}{l}\text { Building outline intact, clear } \\
\text { roof edges, roof damage } \\
\text { resulting in ununiform } \\
\text { color and texture } \\
\text { asymmetry }\end{array}$ & $\begin{array}{l}\text { Building outline relatively } \\
\text { intact, damaged roof edges, } \\
\text { seriously damaged roof, } \\
\text { mixed coloring and texture } \\
\text { disorder }\end{array}$ & $\begin{array}{l}\text { Building outline broken, } \\
\text { damaged roof edges, } \\
\text { seriously damaged roof, } \\
\text { exhibiting collapse, large } \\
\text { amount of rubble }\end{array}$ \\
\hline $\begin{array}{l}\text { Brick- } \\
\text { wood }\end{array}$ & $\begin{array}{l}\text { Building outline intact, clear } \\
\text { roof edges, wooden roof racks } \\
\text { are invisible, no signs of holes } \\
\text { in black blotch }\end{array}$ & $\begin{array}{l}\text { Building outline intact, clear } \\
\text { roof edges, tiles fallen, } \\
\text { signs of holes in black } \\
\text { blotch }\end{array}$ & $\begin{array}{l}\text { Damaged roof edges, tiles } \\
\text { fallen, partly collapsed roof }\end{array}$ & $\begin{array}{l}\text { Building outline broken, } \\
\text { damaged roof edges, tiles } \\
\text { fallen, collapsed roof, } \\
\text { interior building walls are } \\
\text { visible }\end{array}$ \\
\hline Other & $\begin{array}{l}\text { Building outline intact, clear } \\
\text { roof edges, tiles fallen, } \\
\text { wooden roof racks are often } \\
\text { visible, no signs of holes in } \\
\text { black blotch }\end{array}$ & $\begin{array}{l}\text { Building outline intact, clear } \\
\text { roof edges, tiles fallen, } \\
\text { signs of holes in black } \\
\text { blotch }\end{array}$ & $\begin{array}{l}\text { Roof outline intact, damaged } \\
\text { roof edges, tiles fallen, } \\
\text { collapsed roof }\end{array}$ & $\begin{array}{l}\text { Building outline broken, } \\
\text { damaged roof edges, tiles } \\
\text { fallen, collapsed roof, } \\
\text { interior building walls are } \\
\text { visible }\end{array}$ \\
\hline
\end{tabular}

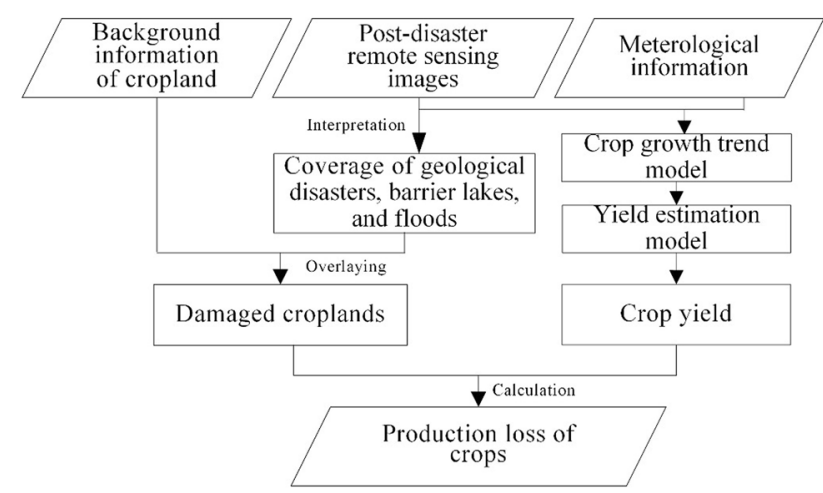

Fig. 3 Diagram of farmland damage assessment

example, arable land, forest land, grassland, and surface water bodies, relatively high-resolution satellite remote sensing data such as GF-1/GF-2 and ZY-3 images are used. These hazard-affected elements are only divided into two damage states: damaged (destroyed) and undamaged. The damage condition can be judged through change detection algorithms (Thunig et al. 2011; Tadono et al. 2012) by comparing pre-disaster and post-disaster remote sensing images. Finally, the damage proportion matrix of these hazard-affected elements within selected monitoring areas can be calculated.

\subsection{Field Survey and Calibration of the Results from Remote Sensing Assessment}

Information from high-resolution remote sensing data obtained by existing Earth observation platforms still possesses blind spots, and, consequently, damage assessment results do not necessarily reflect actual disaster losses. For example, during the Haiti Earthquake, building damage assessment results from high-resolution airborne remote sensing and multi-angle oblique photography gave lower values than the actual damage conditions (Booth et al. 2011). The reason is that remote sensing technology is unable to observe the damage condition of closely grouped building walls. Therefore, a field survey at the time, when the remote sensing monitoring of selected areas is carried out, to obtain more precise and correct field assessment results becomes necessary for calibrating and adjusting the remote sensing assessment results so as to obtain damage proportion matrices that better match actual conditions.

\subsubsection{Collection of Disaster Information from Field Survey}

A field survey mainly covers a limited number of typical sites, which is usually a subarea of the selected remote sensing monitoring areas, to obtain ground truths through household surveys and field interviews. Field survey personnel carry smart mobile terminals (mobile phones and tablet PCs) equipped with background spatial vector data of hazard-affected elements within the survey area and post-disaster remote sensing images. They use a field disaster information collection system with client/server architecture to collect disaster information in the form of text tables, lists, photographs, audio recordings, and videos, and then transmit these data through GPRS or 3G networks to a remote backstage management system located at the National Disaster Reduction Center of China. Personnel in the back office summarize and process the collected data to 
formulate field survey damage proportion matrices for hazard-affected elements.

\subsubsection{Calibration of the Results from Remote Sensing Assessment}

Field survey damage proportion matrices can be used to calibrate damage proportion matrices derived from remote sensing assessment results based on Bayesian principles (Booth et al. 2011). Damage proportions of buildings with various structure types within areas with different disaster damage states obtained from remote sensing assessment are fitted by earthquake vulnerability probability density distribution functions as prior probability density functions. Field survey results are also fitted correspondingly as likelihood functions. Then, a posterior probability function, which is updated under the Bayesian framework, can be used to represent the calibrated results. Based on established results of the probability distribution of earthquake vulnerability, it is assumed that the prior function has the form of a beta-distribution (Spence et al. 2008), and the likelihood function, which is fitted using field surveys as observational data, also follows a beta-distribution, and therefore the posterior distribution also has a beta-distribution. By taking the expected value of various posterior beta-distributions as the damage proportion of buildings with various structure types in different disaster-affected areas, a new and calibrated damage proportion matrix is obtained.
For other hazard-affected elements, a vulnerability curve based on previous research results can be used to construct new prior and observational probability distribution functions for calibration.

\subsection{Disaster Index Calculation by GIS}

Combined with background data of various hazard-affected elements, the calibrated damage proportion matrix is used as the overall damage proportion matrix to carry out GIS spatial analysis, and quantified damage indices of the quantitative assessment index system in different disaster areas can be estimated, such as the number of damaged rooms with different structure types and different damage states. Quantitative assessment results of physical damage using remote sensing data can be obtained.

\section{A Case Study of the 2014 Ludian Earthquake}

At 16:30 on 3 August 2014, a magnitude 6.5 earthquake occurred in Ludian County, Zhaotong City, Yunnan Province, which caused serious casualties and property damage. According to the survey results on the seismic intensity in the disaster area, provided by the China Earthquake Administration, there were 16 seriously damaged towns (Table 4) within the three counties of Ludian, Qiaojia, and Huize that are encircled by the VII-degree seismic intensity line (Fig. 4). The State Council of China authorized the Ministry of Civil Affairs and the

Table 4 Number of buildings with different structure types in the 16 seriously damaged towns within the VII-degree seismic intensity line of the 2014 Ludian Earthquake, Yunnan Province, China

\begin{tabular}{|c|c|c|c|c|c|c|}
\hline \multirow[t]{2}{*}{ County } & \multirow[t]{2}{*}{ Town } & \multicolumn{5}{|c|}{ Number of buildings } \\
\hline & & Steel-concrete & Brick-concrete & Brick-wood & Other & Subtotal \\
\hline \multirow[t]{9}{*}{ Ludian } & Longtoushan & 158 & 3696 & 904 & 13,735 & 18,493 \\
\hline & Huodehong & 162 & 718 & 36 & 4242 & 5158 \\
\hline & Shuimo & 333 & 1948 & 1846 & 5130 & 9257 \\
\hline & Lehong & 137 & 578 & 202 & 6433 & 7350 \\
\hline & Xiaozhai & 121 & 163 & 459 & 3988 & 4731 \\
\hline & Wenping & 34 & 1478 & 232 & 2449 & 4193 \\
\hline & Jiangdi & 32 & 506 & 222 & 1795 & 2555 \\
\hline & Suoshan & 30 & 498 & 237 & 1833 & 2598 \\
\hline & Longshu & 0 & 53 & 10 & 121 & 184 \\
\hline \multirow[t]{5}{*}{ Qiaojia } & Xindian & 46 & 655 & 103 & 9488 & 10,292 \\
\hline & Xiaohe & 59 & 274 & 579 & 4693 & 5605 \\
\hline & Laodian & 207 & 1853 & 375 & 16,060 & 18,495 \\
\hline & Yaoshan & 3 & 113 & 68 & 1183 & 1367 \\
\hline & Baogu'nao & 109 & 1306 & 435 & 5647 & 7497 \\
\hline \multirow[t]{2}{*}{ Huize } & Zhichang & 160 & 783 & 63 & 5250 & 6256 \\
\hline & Yiche & 131 & 473 & 345 & 2294 & 3243 \\
\hline
\end{tabular}




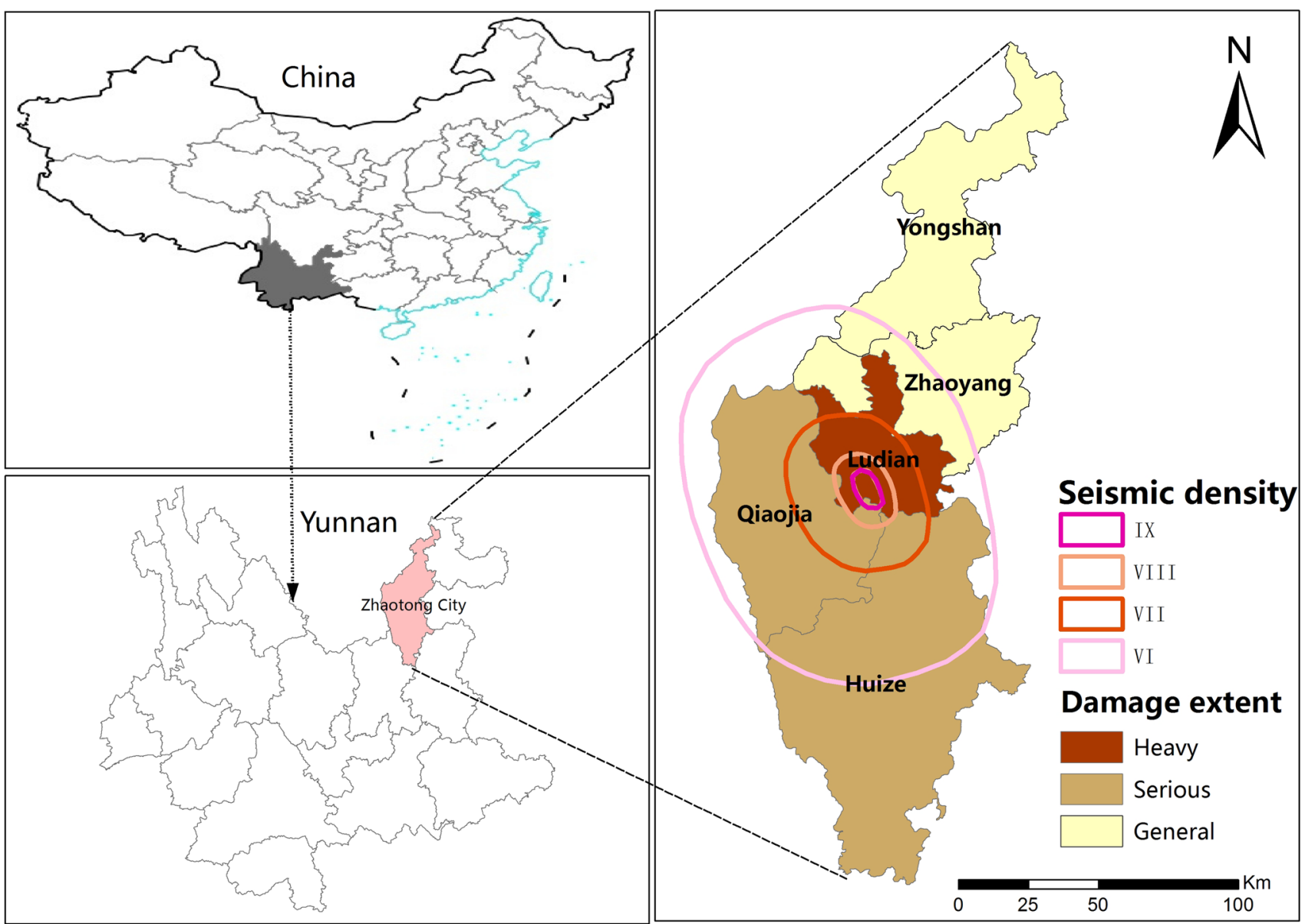

Fig. 4 Disaster extent of the 2014 Ludian Earthquake, Yunnan Province, China

Government of Yunnan Province to organize a group of experts to implement a comprehensive assessment of earthquake damage. The National Disaster Reduction Center of China urgently initiated a National Major Natural Disaster UAV Emergency Response Cooperation Mechanism, the International Charter "Space and Major Disasters," and other mechanisms to coordinate relevant Chinese and international organization in acquiring satellite, airborne, and UAV remote sensing data of the disaster region. By using remote sensing data, a quantitative assessment of physical damage of buildings, transportation lines, farming and forestry, and secondary geological disasters was implemented.

\subsection{Building Damage Assessment}

According to the quantitative assessment method, building damage assessment mainly includes four steps: pre-disaster background information extraction, post-disaster remote sensing damage assessment of selected areas, field survey and calibration, and disaster index calculation by GIS.

\subsubsection{Pre-Disaster Background Information Extraction}

Wide-range WorldView-2 satellite images (approximately $0.5 \mathrm{~m}$ spatial resolution) from 2012 and 2013 were used to extract building background spatial information within the VII-degree seismic intensity line, to derive building outlines through visual interpretation, and to infer the storeys and structure types of buildings from their shadows and roof patterns. The number of buildings with different structure types in each of the 16 seriously damaged towns was counted. The results are shown in Fig. 5 and Table 4.

\subsubsection{Post-Disaster Remote Sensing Damage Assessment}

Remote sensing monitoring was implemented for selected typical disaster-affected towns within the VII, VIII, and IX-degree seismic intensity zones according to reported disaster information from local governments using $0.1 \mathrm{~m}$ resolution UAV remote sensing images. According to the damage condition, building damage interpretation keys were established from UAV images (Fig. 6) and the 


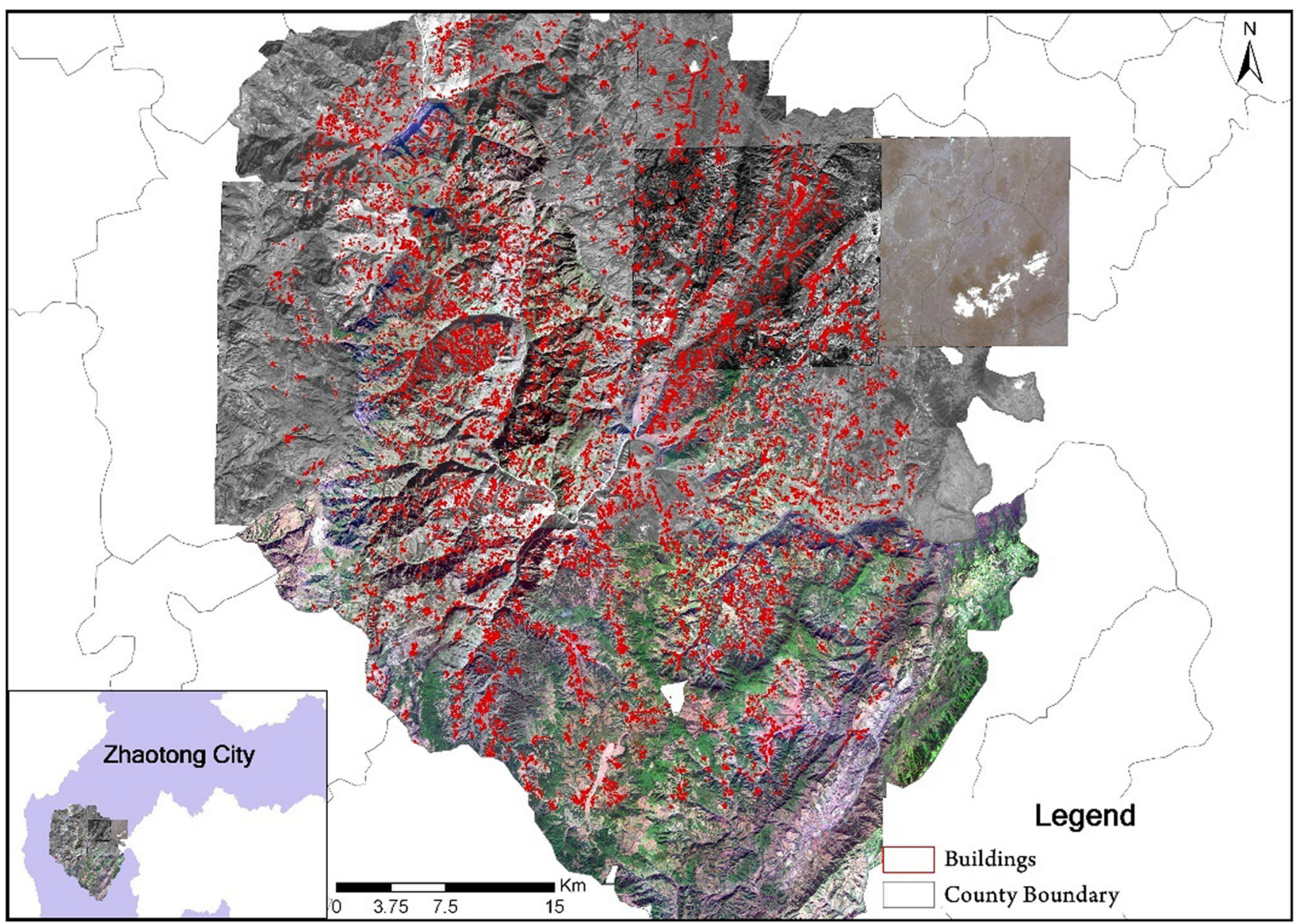

Fig. 5 Building distribution within the VII-degree seismic intensity line of the 2014 Ludian Earthquake, Yunnan Province, China

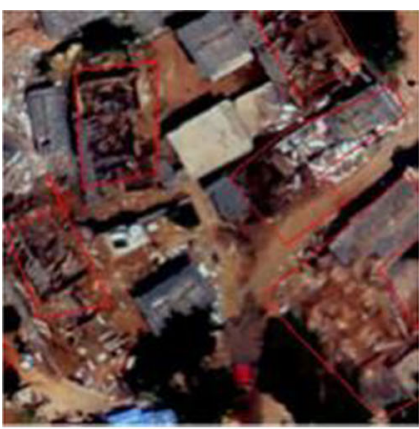

(a)

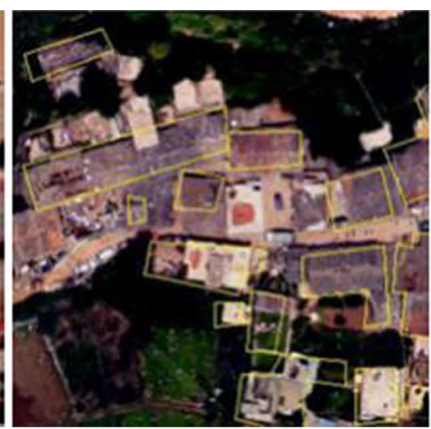

(b)

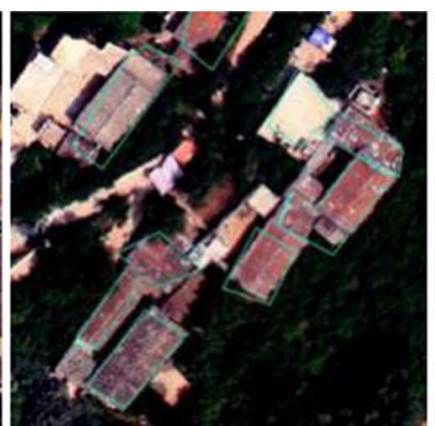

(c)

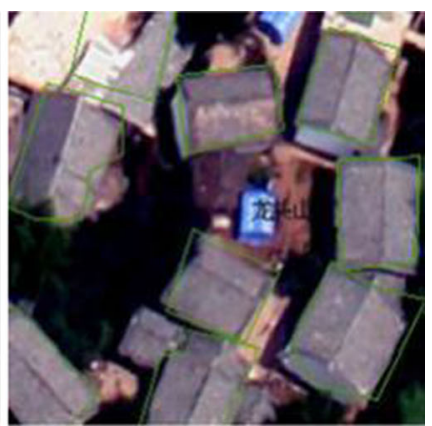

(d)

Fig. 6 Building damage interpretation keys (UAV images): Totally collapsed (a), Seriously damaged (b), Moderately damaged (c), Undamaged (d)

damage states of buildings within these towns were assigned (Fig. 7). The damage proportion matrix of buildings with various structure types within the VIIdegree seismic intensity line was then obtained, as shown in Table 5.

\subsubsection{Field Survey and Calibration}

An experts group for field investigation surveyed the postdisaster remote sensing monitoring area at representative disaster-affected locations within the VII, VIII, IX-degree seismic intensity zones, and calibrated the damage 


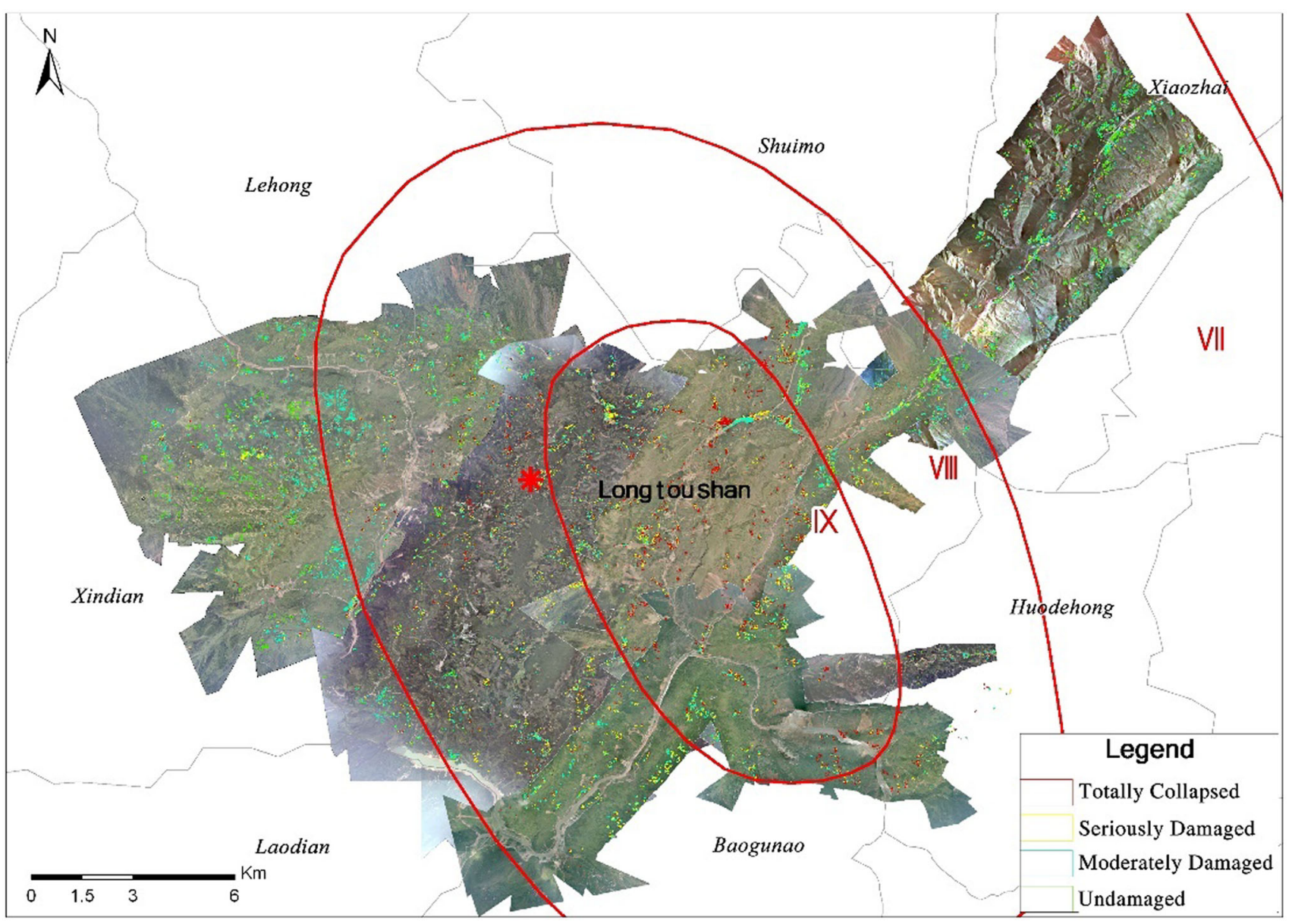

Fig. 7 Assessment result of building damage caused by the 2014 Ludian Earthquake in Yunnan Province, using UAV remote sensing images

Table 5 Building damage proportion matrix from remote sensing analysis of selected typical areas within the VII-degree seismic intensity line of the 2014 Ludian Earthquake, Yunnan Province, China

\begin{tabular}{|c|c|c|c|c|c|}
\hline Intensity degree & Structure type & Totally collapsed (\%) & Seriously damaged $(\%)$ & Moderately damaged (\%) & Undamaged $(\%)$ \\
\hline \multirow[t]{4}{*}{ IX } & Steel-concrete & 0 & 13.13 & 52.09 & 34.78 \\
\hline & Brick-concrete & 20.83 & 33.74 & 44.30 & 1.12 \\
\hline & Brick-wood & 50.38 & 24.24 & 24.26 & 1.12 \\
\hline & Other & 39.36 & 32.23 & 27.21 & 1.20 \\
\hline \multirow[t]{4}{*}{ VIII } & Steel-concrete & 0.00 & 39.97 & 28.65 & 31.39 \\
\hline & Brick-concrete & 8.96 & 23.58 & 36.63 & 30.83 \\
\hline & Brick-wood & 15.72 & 29.55 & 39.98 & 14.75 \\
\hline & Other & 20.64 & 29.85 & 36.95 & 12.56 \\
\hline \multirow[t]{4}{*}{ VII } & Steel-concrete & 0.00 & 8.20 & 62.30 & 27.05 \\
\hline & Brick-concrete & 5.39 & 31.42 & 36.30 & 26.88 \\
\hline & Brick-wood & 1.20 & 13.92 & 30.12 & 54.76 \\
\hline & Other & 3.62 & 12.87 & 39.35 & 44.16 \\
\hline
\end{tabular}

proportion matrix using Bayesian principles. A calibrated damage proportion matrix was then obtained, as shown in Table 6.

\subsubsection{Disaster Index Calculation by GIS}

The areas of buildings with various damage states and various structure types within different seismic intensity 
Table 6 Calibrated building damage proportion matrix for the 2014 Ludian Earthquake, Yunnan Province, China

\begin{tabular}{|c|c|c|c|c|c|}
\hline Intensity degree & Structure type & Totally collapsed (\%) & Seriously damaged $(\%)$ & Moderately damaged (\%) & Undamaged $(\%)$ \\
\hline \multirow[t]{4}{*}{ IX } & Steel-concrete & 0 & 31.41 & 42.53 & 26.06 \\
\hline & Brick-concrete & 21.87 & 30.63 & 45.43 & 2.06 \\
\hline & Brick-wood & 49.65 & 28.84 & 17.56 & 3.94 \\
\hline & Other & 47.93 & 27.36 & 23.65 & 1.06 \\
\hline \multirow[t]{4}{*}{ VIII } & Steel-concrete & 0.00 & 32.81 & 26.79 & 40.40 \\
\hline & Brick-concrete & 9.46 & 25.73 & 33.50 & 31.31 \\
\hline & Brick-wood & 25.38 & 26.94 & 37.30 & 10.38 \\
\hline & Other & 17.28 & 28.41 & 42.69 & 11.62 \\
\hline \multirow[t]{4}{*}{ VII } & Steel-concrete & 0.00 & 21.13 & 23.30 & 55.57 \\
\hline & Brick-concrete & 5.79 & 35.11 & 35.97 & 23.12 \\
\hline & Brick-wood & 2.03 & 12.22 & 42.38 & 43.37 \\
\hline & Other & 2.98 & 11.45 & 44.56 & 41.01 \\
\hline
\end{tabular}

regions was calculated by conducting a GIS spatial analysis using the calibrated building damage proportion matrix in conjunction with background spatial data within the VIIdegree seismic intensity line. An average area of $25 \mathrm{~m}^{2}$ per room was determined according to field survey and interview results, and the quantitative assessment results of physical damage of buildings using remote sensing data in the 16 seriously damaged towns within the VII-degree seismic intensity line were obtained as shown in Table 7.

\subsection{Secondary Geological Disaster Monitoring}

According to the disaster conditions reported by the local governments, the damage to infrastructure such as roads, farmland, and forest resources from the 2014 Ludian Earthquake was mainly caused by landslides and other secondary geological hazards. The coverage of secondary geological hazards was first interpreted and assessed using UAV images and SS-9 satellite data, and the numbers, categories, areas, and distributions of landslides and rock slides were extracted (Fig. 8).

A total of 604 landslides and rock slides were interpreted, covering an area of 8.83 million $\mathrm{m}^{2}$ and mainly distributed along the rivers and roads within the IX and VIII-degree seismic intensity zones. Among these, there were 149 moderate landslides (area of slide larger than $100 \mathrm{~m} \times 100 \mathrm{~m}$ ), which covered an area of 7.8 million $\mathrm{m}^{2}$, and 455 minor landslides (area of slide smaller than $100 \mathrm{~m} \times 100 \mathrm{~m}$ ), which covered an area of 1.03 million $\mathrm{m}^{2}$.

\subsection{Road Damage Assessment}

Pre-disaster background vector data on various grades of roads within the VII-degree seismic intensity line were prepared based on road data from China's 1:25,000 basic geographical data, OpenStreetMap public data, and basic data of provincial and county roads of Yunnan Province. The damage condition of the roads was determined by overlaying the secondary geological hazard vector obtained through image interpretation and the road vector file (Fig. 8).

A total of $31,197 \mathrm{~m}$ of damaged roads suffered from secondary geological disasters such as landslides and rock slides, and these were mainly distributed in Ludian County and Qiaojia County in Zhaotong City, including $5373 \mathrm{~m}$ of seriously damaged and unusable roads, $7540 \mathrm{~m}$ of moderately damaged and slightly affected roads, and 18,284 m of slightly damaged roads with normal passing capabilities.

\subsection{Land Resource Damage Assessment}

Pre-disaster background spatial vector data of farmland and forest resources within the VII-degree seismic intensity line were prepared based on the Second National Land Survey data. The damage condition of farmland and forest was then assessed by overlaying and analyzing the coverage range of secondary geological hazard areas (Fig. 8).

A total area of 1226.4 hectares was affected by secondary geological disasters such as landslides, damaged farmland, and forests, including 199.5 hectares of forest land, 402.5 hectares of shrub land, 280.2 hectares of other forest land, 2.3 hectares of paddy fields, and 341.9 hectares of dry land.

\section{Discussion}

The developed index system and assessment method constitute a relatively complete and rigorous framework for disaster damage assessment that can take full advantage of various sources of data. However, despite its practical 


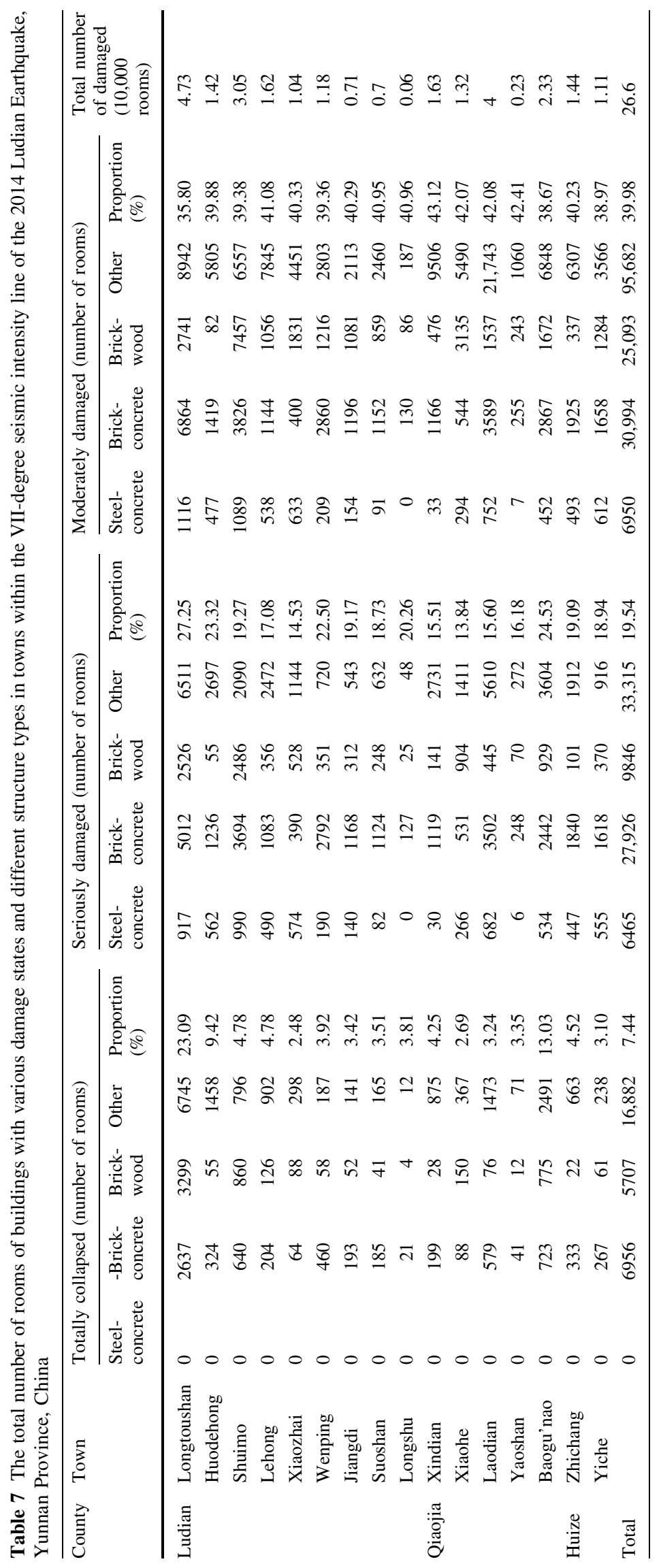




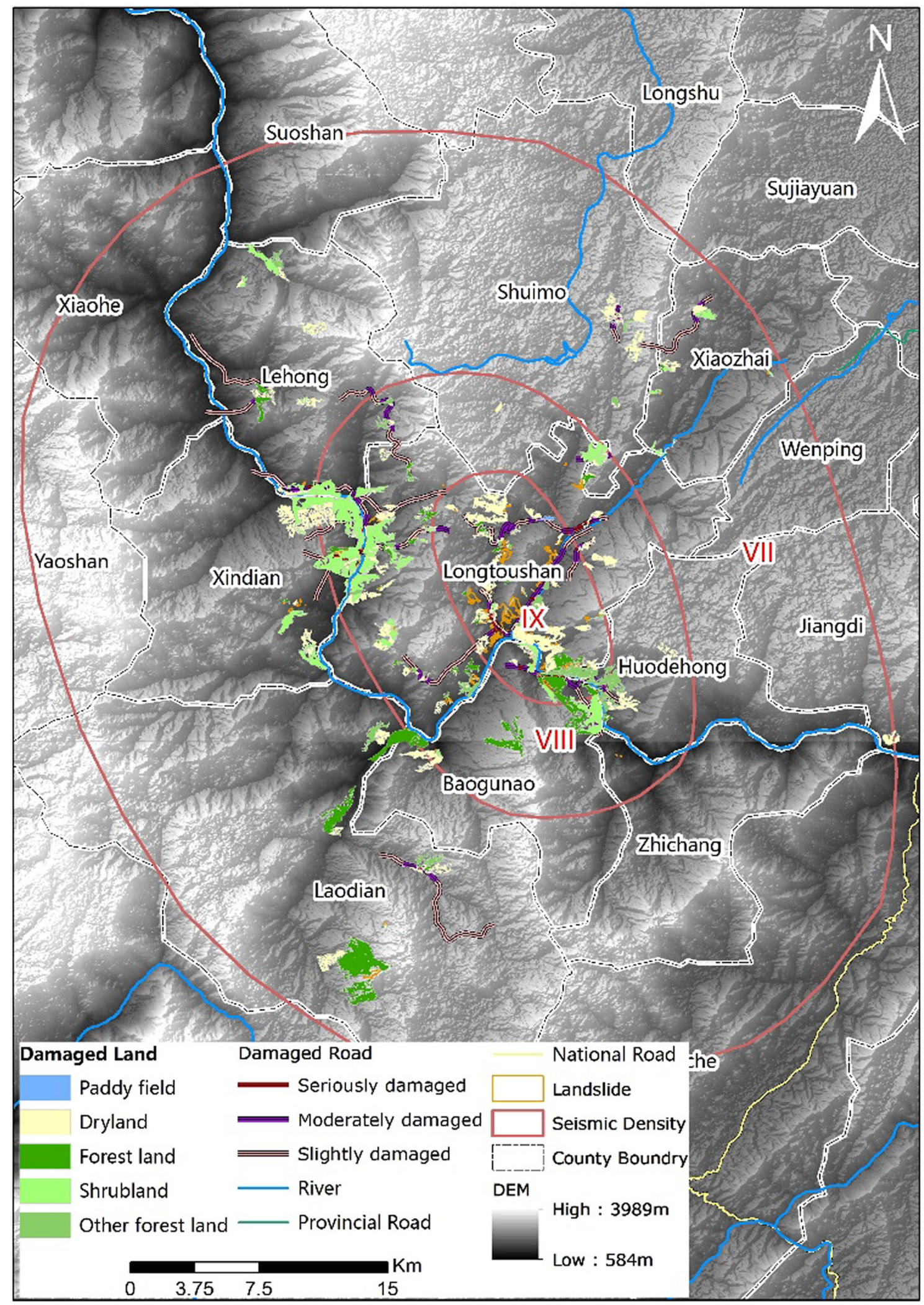

Fig. 8 Secondary geological hazards caused by the 2014 Ludian Earthquake, Yunnan Province, and road and land resource damages induced by secondary hazards 
value, there are some issues with the method that still need to be addressed:

1. The preparation of background information of hazardaffected elements included in the quantitative assessment index system by visual interpretation from remote sensing data often requires the participation of relatively large numbers of personnel. Though some semiautomatic algorithms have been developed to aid visual interpretation, to vectorize physical objects from a huge amount of remote sensing data is still very time-consuming and expensive work. The latest progress in artificial intelligence such as the Convolution Neural Network (CNN) has brought computer vision technology into practice. CNN-based image classification algorithms, object identification algorithms, and image segmentation algorithms can also be adapted for remote sensing images to improve fully automatic information extraction so that efficiency will be increased and cost will be decreased.

2. Existing high-resolution remote sensing data cannot yet provide sufficiently accurate information to determine structure type with the desired precision. Even on site, structure types of some buildings, especially for brick-concrete and brick-wood buildings, cannot be distinguished from outer walls and roofs. New kinds of higher-resolution remote sensing satellites are required, for example, satellites carrying high-spatial resolution thermal infrared cameras have the potential to provide accurate spectrum information for structure type identification over a wide range.

3. Post-disaster remote sensing surveys mainly use UAVs equipped with optical sensors to acquire orthographic images. However, there exist blind spots in building damage survey, such as an inability to observe damage information on side walls and interior structures. It is necessary to develop specialized sensors (for example, multi-angle oblique photography and thermal infrared cameras) mounted on UAVs to monitor building damage, thereby improving the precision of the building damage proportion matrix.

4. The results of Earth observation and field survey data integration can provide calibration of remote sensing assessment results. In addition to the development of more easily operable disaster information collection systems, further standardization should be pursued in field surveys, and existing national and industry standards should be strictly followed in practice in order to obtain more reliable survey results. Methods of calibration of remote sensing assessment results using field survey data need to be further investigated with the development of targeted calibration methods for various hazard-affected elements, and more accurate vulnerability curves need to be introduced.

\section{Conclusion}

Disaster damage assessment results are the foundation of disaster relief, recovery, and reconstruction planning. Owing to its characteristics of rapid response and wide coverage, remote sensing technology can provide effective information for disaster damage assessment. The index system and method for quantitative remote sensing assessment that incorporate satellite and UAV remote sensing data and field survey data have been applied to the damage assessment work of several major natural hazardinduced disasters in China. The case of the 2014 magnitude 6.5 Ludian Earthquake demonstrates that the developed index system and method can significantly improve the effectiveness, applicability, and scientific validity of disaster damage assessment.

Acknowledgements This work was partially supported by the National Natural Science Foundation of China (Grant No. 41301485), the High Resolution Earth Observation System (National Science and Technology Major Project), and the National High Technology Research and Development Program of China (Grant No. 2012AA121305). The authors are grateful to the Ministry of Land and Resources, the National Administration of Surveying, Mapping and Geoinformation, the Ministry of Transport, the CHARTER mechanism, and other institutes and partnership mechanisms for supporting this research and for help in data acquisition.

Open Access This article is distributed under the terms of the Creative Commons Attribution 4.0 International License (http://crea tivecommons.org/licenses/by/4.0/), which permits unrestricted use, distribution, and reproduction in any medium, provided you give appropriate credit to the original author(s) and the source, provide a link to the Creative Commons license, and indicate if changes were made.

\section{References}

Booth, E., K. Saito, R. Spence, G. Madabhushi, and R.T. Eguchi. 2011. Validating assessments of seismic damage made from remote sensing. Earthquake Spectra 27(S1): S157-S177.

Cao, C.X., D. Liu, R.P. Singh, S. Zheng, R. Tian, and H.J. Tian. 2015. Integrated detection and analysis of earthquake disaster information using airborne data. Geomatics, Natural Hazards and Risk 7(3): 1-30.

Chiroiu, L. 2005. Damage assessment of the 2003 Bam, Iran, earthquake using Ikonos imagery. Earthquake Spectra 21(S1): S219-S224.

Corbane, C., K. Saito, L. Dell'Oro, E. Bjorgo, S.P.D. Gill, B.E. Piard, C.K. Huyck, T. Kemper, et al. 2011. A comprehensive analysis of building damage in the 12 January 2010 Mw7 Haiti Earthquake using high-resolution satellite and aerial imagery. Photogrammetric Engineering and Remote Sensing 77(10): 997-1009. 
Deng, Y., and B.S. Manjunath. 2001. Unsupervised segmentation of color-texture regions in images and video. IEEE Transactions on Pattern Analysis and Machine Intelligence 23(8): 800-810.

Du, L.L., Q.J. Tian, T. Yu, Q.Y. Meng, T. Jancso, P. Udvardyd, and Y. Huang. 2013. A comprehensive drought monitoring method integrating MODIS and TRMM data. International Journal of Applied Earth Observation and Geoinformation 23(1): 245-253.

Ehrlich, D., H.D. Guo, K. Molch, J.W. Ma, and M. Pesaresi. 2009. Identifying damage caused by the 2008 Wenchuan Earthquake from VHR remote sensing data. International Journal of Digital Earth 2(4): 309-326.

Experts Group for Earthquake Disaster Relief, National Disaster Reduction Committee and Ministry of Science and Technology. 2008. Comprehensive analysis and assessment of the Wenchuan Earthquake disaster. Beijing: Science Press (in Chinese).

Fan, Y.D. 2014. Study on space data sharing mechanism for major natural disaster emergency. Beijing: Science Press (in Chinese).

Fan, Y.D., Q. Wen, and S.R. Chen. 2012. Engineering survey of the Environment and Disaster Monitoring and Forecasting Small Satellite Constellation. International Journal of Digital Earth 5(3): 217-227.

Fan, Y.D., S.Q. Yang, L. Wang, W. Wang, J. Nie, and B.J. Zhang. 2008. Study on urgent monitoring and assessment in Wenchuan Earthquake. Journal of Remote Sensing 12(6): 858-864.

Graciela M., H. Lorenz, G. Radu. 2005. Remote sensing of landslides: An analysis of the potential contribution to geo-spatial systems for hazard assessment in mountainous environments. Remote Sensing of Environment 98(2-3):284-303.

Grünthal, G. (ed.). 1998. European macroseismic scale 1998 (EMS98). European Seismological Commission, Subcommission on Engineering Seismology, Working Group Macroseismic Scales, Luxembourg.

Kohiyama, M., and F. Yamazaki. 2005. Damage detection for 2003 Bam, Iran, Earthquake using Terra-ASTER satellite imagery. Earthquake Spectra 21(S1): S267-S274.

Li, Q.Z., F.F. Zhang, X. Du, B.F. Wu, L. Zhang, Y.C. Wei, and J.H. Meng. 2009. Grain loss in main disaster area caused by Wenchuan Earthquake. Journal of Remote Sensing 13(5): 928-939.

Liang, T.G., X.D. Huang, C.X. Wu, X.Y. Liu, W.L. Li, Z.G. Guo, and J.Z. Ren. 2008. An application of MODIS data to snow cover monitoring in a pastoral area: A case study in Northern Xinjiang, China. Remote Sensing of Environment 112(4): 1514-1526.

Liu, W., F. Yamazaki, H. Gokon, and S. Koshimura. 2013. Extraction of tsunami-flooded areas and damaged buildings in the 2011 Tohoku-Oki Earthquake from TerraSAR-X intensity images. Earthquake Spectra 29(S1): S183-S200.

Liu, Z., P. Gong, P.J. Shi, H. Chen, L. Zhu, and T. Sasagawa. 2010. Automated building change detection using UltraCamD images and existing CAD data. International Journal of Remote Sensing 31(6): 1505-1517.

Maruyama, Y., F. Yamazaki, S. Matsuzaki, H. Miura, and M. Estrada. 2012. Evaluation of building damage and tsunami inundation based on satellite images and GIS data following the 2010 Chile Earthquake. Earthquake Spectra 28(S1): S165-S178.

Matsuoka, M., and F. Yamazaki. 2005. Building damage mapping of the 2003 Bam, Iran, Earthquake using Envisat/ASAR intensity imagery. Earthquake Spectra 21(S1): S285-S294.

Ministry of Civil Affairs and National Bureau of Statistics. 2014. Major Natural Disaster Damage Statistics System. http://xxgk. mca.gov.cn/n1360/n51127.files/n51128.pdf. Accessed 17 Sept 2014 (in Chinese).

Nie, J., S.H. Du, Y.D. Fan, S.Q. Yang, H.X. He, Y. Cui, and W. Zhang. 2016. Estimating the numbers and the areas of collapsed buildings by combining VHR images, statistics and survey data: A case study of the Lushan Earthquake in China. Journal of the Indian Society of Remote Sensing 44(1): 101-110.
Spence, R., E. So, S. Jenny, H. Castella, M. Ewald, and E. Booth. 2008. The Global Earthquake Vulnerability Estimation System (GEVES): An approach for earthquake risk assessment for insurance applications. Bulletin of Earthquake Engineering 6(3): $463-483$.

Stramondo, S., C. Bignami, M. Chini, N. Pierdicca, and A. Tertulliani. 2006. Satellite radar and optical remote sensing for earthquake damage detection: Results from different case studies. International Journal of Remote Sensing 27(20): $4433-4447$.

Tadono, T., S. Hashimoto, M. Onosato, and M. Hori. 2012. Applications of the automatic change detection for disaster monitoring by the knowledge-based framework. In Proceedings of SPIE Earth Observing Missions and Sensors: Development, Implementation, and Characterization II. 9 November 2011, Kyoto, Japan. Paper No. 85280T.

Thunig, H., U. Michel, M. Ehlers, and P. Reinartz. 2011. Objectbased rapid change detection for disaster management. In Proceedings of SPIE Earth Resources and Environmental Remote Sensing/GIS Applications II. 26 October 2011, Prague, Czech Republic. Paper No. 81810N.

Tomppo, E., M. Nilsson, M. Rosengren, P. Aalto, and P. Kennedy. 2002. Simultaneous use of Landsat-TM and IRS-1C WIFS data in estimating large area tree stem volume and aboveground biomass. Remote Sensing of Environment 82(1): 156-171.

Veraverbeke, S., S. Lhermitte, W.W. Verstraeten, and R. Goossens. 2010. The temporal dimension of differenced normalized burn ratio (dNBR) fire/burn severity studies: The case of the large 2007 Peloponnese wildfires in Greece. Remote Sensing of Environment 114(11): 2548-2563.

Wang, D.Z., and H.Y. He. 2017. Observation capability and application prospect of GF-4 satellite. 3rd International Symposium of Space Optical Instruments and Applications. Springer Proceedings in Physics 192: 393-401.

Wang, F., and J. Zhou. 2009. Use of remote sensing in the second national land investigation in China. In Proceedings of SPIE Second International Conference on Earth Observation for Global Changes. International Society for Optics and Photonics. 25-29 May 2009, Chengdu, China. Paper No. 747108.

Wang, L., R.R. Yang, Q.J. Tian, Y.J. Yang, Y. Zhou, Y. Sun, and X.F. Mi. 2015. Comparative analysis of GF-1 WFV, ZY-3 MUX, and HJ-1 CCD sensor data for grassland monitoring applications. Remote Sensing 7(2): 2089-2108.

Wang, W., J.J. Qu, X.J. Hao, Y.Q. Liu, and J.A. Stanturf. 2010. Posthurricane forest damage assessment using satellite remote sensing. Agricultural and Forest Meteorology 150: 122-132.

Wen, Q., H.X. He, X.F. Wang, W. Wu, L. Wang, F. Xu, P. Wang, T. Tang, and Y. Lei. 2011. UAV remote sensing hazard assessment in Zhouqu Debris Flow disaster. In Proceedings of SPIE European Remote Sensing. 18-21 September 2011, Prague, Czech Republic, Paper No. 817510.

Wen, Q., F. Xu, and S.R. Chen. 2011. Remote sensing hazard monitoring and assessment in Yushu Earthquake disaster. In Proceedings of SPIE International Symposium on Multispectral Image Processing and Pattern Recognition. 4-8 November 2011, Guilin, China, Paper No. 80061W.

Wu, B.F., L. Zhang, X.F. Yu, Z.M. Wang, R.H. Ma, J.L. Huang, A.N Li, J.C. Chen, et al. 2013. ChinaCover 2010: Methodology and features. In Proceedings of the 8th International Symposium on Digital Earth. 26-29 August 2013, Sarawak, Malaysia.

Yamazaki, F., Y. Yano, and M. Matsuoka. 2005. Visual damage interpretation of buildings in Bam City using QuickBird images following the 2003 Bam, Iran, Earthquake. Earthquake Spectra 21(S1): S329-S336.

Yang, S.Q., S.C. Liu, W. Wu, L. Wang, F. Xu, H.X. He, W. Zhang, Q. Wen, et al. 2011. Remote sensing applications in Qinghai Yushu 
Earthquake monitoring and assessment. Spacecraft Engineering 20(2): 90-96 (in Chinese).

Ye, Z.W., C.B. Deng, and H.L. Gong. 2008. Acquiring height distribution information about high-rises in Beijing using shadow in SPOT-5. In Proceedings of SPIE Geoinformatics 2008 and Joint Conference on GIS and Built Environment: Classification of Remote Sensing Images. International Society for Optics and Photonics. 28-29 June 2008, Guangzhou, China. Paper No. 71470S.

Zhang, J.X., X.G. Lin, Z.J. Liu, and J. Shen. 2011. Semi-automatic road tracking by template matching and distance transformation in urban areas. International Journal of Remote Sensing 32(23): 8331-8347.

Zhang, Y., Y. Wan, B. Wang, Y. Kang, and J. Xiong. 2015. Automatic processing of Chinese GF-1 Wide Field of View Images. International Archives of the Photogrammetry, Remote Sensing and Spatial Information Sciences. XL-7/W3 (7): 729-734.

Zhao, D., M. Zhang, M.Z. Yu, Y. Zeng, and B.F Wu. 2014. Monitoring agriculture and forestry recovery after the Wenchuan Earthquake. Journal of Remote Sensing 18(4): 958-970 (in Chinese). 